\title{
Ribulose-1,5-bisphosphate carboxylase/oxygenase genes as a functional marker for chemolithoautotrophic halophilic sulfur-oxidizing bacteria in hypersaline habitats
}

\begin{abstract}
Correspondence
Tatjana P. Tourova

tptour@rambler.ru
\end{abstract}

Received 14 September 2009

Revised 12 March 2010

Accepted 18 March 2010

\author{
Tatjana P. Tourova, ${ }^{1}$ Olga L. Kovaleva, ${ }^{2}$ Dimitry Yu. Sorokin ${ }^{1,3}$ \\ and Gerard Muyzer ${ }^{3}$
}

\author{
${ }^{1}$ Institute of Microbiology, Russian Academy of Sciences, p-t 60-letiya Oktyabrya, 7/2, Moscow, \\ Russia \\ ${ }^{2}$ Department of Microbiology, Moscow State University, Moscow, Russia \\ ${ }^{3}$ Department of Biotechnology, Delft University of Technology, Delft, The Netherlands
}

\begin{abstract}
The presence and diversity of the cbb genes encoding the large subunit of ribulose-1, 5-bisphosphate carboxylase/oxygenase (RuBisCO) (a key enzyme of the Calvin-Benson cycle of autotrophic $\mathrm{CO}_{2}$ assimilation) were investigated in pure cultures of seven genera of halophilic chemolithoautotrophic sulfur-oxidizing bacteria (SOB) and in sediments from a hypersaline lake in which such bacteria have been recently discovered. All of the halophilic SOB strains (with the exception of Thiohalomonas nitratireducens) possessed the cbbL gene encoding RuBisCO form I, while the $c b b M$ gene encoding RuBisCO form II was detected only in some of the pure cultures. The general topologies of the CbbL/CbbM trees and the 16S rRNA gene tree were different, but both markers showed that the halophilic SOB genera formed independent lineages in the Gammaproteobacteria. In some cases, such as with several strains of the genus Thiohalospira and with Thioalkalibacter halophilus, the $c b b L$ clustering was incongruent with the positions of these strains on the ribosomal tree. In the $c b b M$ tree, the clustering of Thiohalospira and Thiohalorhabdus strains was incongruent with their branching in both $c b b L$ and 16S rRNA gene trees. $c b b L$ and $c b b M$ genes related to those found in the analysed halophilic SOB were also detected in a sediment from a hypersaline lake in Kulunda Steppe (Russia). Most of the cbbL and $c b b M$ genes belonged to members of the genus Thiohalorhabdus. In the $c b b L$ clone library, sequences related to those of Halothiobacillus and Thiohalospira were detected as minor components. Some of the environmental cbbM sequences belonged to as yet unknown phylotypes, representing deep lineages of halophilic autotrophs.
\end{abstract}

\section{INTRODUCTION}

The detection of key functional genes provides an excellent tool to study autotrophic microbial communities in situ without cultivation biases. In contrast to $16 \mathrm{~S}$ rRNA genebased molecular screening, protein-encoding gene analysis allows a focus on that part of the microbial community responsible for a particular function. In many cases,

Abbreviations: RuBisCO, ribulose-1,5-bisphosphate carboxylase/oxygenase; SOB, sulfur-oxidizing bacteria.

The GenBank/EMBL/DDBJ accession numbers for the sequences reported in this paper are G0888578-GQ888579 (for the 16S rRNA gene), G0888580-G0888605 and GQ888626-G0888632 (for the cbbL gene), and G0888606-G0888625 (for the cbbM gene).

Six supplementary figures, showing primer sets, amino acid sequence alignments, and 16S rDNA-, CbbL- and CbbM-based phylogenetic trees, are available with the online version of this paper. functionally very important groups of the Bacteria and Archaea, such as the chemolithoautotrophs, are present in very low numbers, rendering them undetectable by $16 \mathrm{~S}$ rRNA-based phylogenetic surveys. One such example are the chemolithoautotrophic sulfur-oxidizing bacteria (SOB), which have two sets of functional molecular markers: those encoding sulfur-oxidizing enzymes and those encoding autotrophic carbon assimilation. Since functional genes of the sulfur-oxidation pathways are not conserved and have only recently started to become the subject of molecular analysis (Friedrich et al., 2001, 2005; Loy et al. 2009), the use of the $c b b$ genes [encoding the large ribulose-1,5-bisphosphate carboxylase/oxygenase (RuBisCO) subunit, a key enzyme of the Calvin-Benson cycle of autotrophic $\mathrm{CO}_{2}$ fixation] as a molecular marker is an obvious choice. The $c b b$ genes have been frequently used to analyse marine microbial communities, but rarely 
to study autotrophic communities in extreme habitats, such as hypersaline lakes. Hitherto, the distribution and diversity of the $c b b$ genes have been studied in detail only in the alkaline and saline Mono Lake, California (Giri et al., 2004).

The Calvin cycle of autotrophic $\mathrm{CO}_{2}$ fixation is the most widespread pathway among the aerobic members of the Alpha-, Beta- and Gammaproteobacteria, and is the only autotrophic cycle in Cyanobacteria and in chloroplasts of algae and plants. The key enzyme of the cycle is RuBisCO, which naturally exists in several forms. Proteobacteria contain RuBisCO forms I and II, whose large subunits are encoded by the $c b b L$ and $c b b M$ genes, respectively.

In our previous work, we characterized the $c b b$ gene in pure cultures of haloalkaliphilic SOB belonging to the Thiomicrospira-Thioalkalimicrobium group (Tourova et al., 2006) and to the family Ectothiorhodospiraceae (Tourova et al., 2007). Recently, we discovered an unexpectedly high culturable diversity of moderately and extremely halophilic obligately chemolithoautotrophic SOB in sediments of various hypersaline habitats with neutral $\mathrm{pH}$, including chloride-sulfate inland lakes in Mongolia, Russia and Ukraine, a sea saltern in Slovenia and deep-sea salt brine from the Mediterranean Sea (Sorokin et al., 2006a). Moderately halophilic aerobic SOB include novel species of the known genera Halothiobacillus and Thiomicrospira (Sorokin et al., 2006b), while denitrifying halophiles and extreme halophiles are represented by six novel SOB genera within the Gammaproteobacteria: Thiohalophilus (Sorokin et al., 2007a), Thiohalomonas (Sorokin et al., 2007b), Thiohalospira (Sorokin et al., 2008a), Thiohalorhabdus (Sorokin et al., 2008b), Thioalkalibacter (Banciu et al., 2008) and Thiohalobacter (Sorokin et al., 2010). Among these halophilic SOB, the $c b b$ genes have so far been analysed only in the type species of the genus Halothiobacillus, Halothiobacillus neapolitanus, which contains both forms of RuBisCO genes.

To further advance this line of research, we tested the existing collection of pure cultures of halophilic chemolithoautotrophic SOB strains for the presence of $c b b$ genes. In addition, a culture-independent study of the diversity of $c b b$ genes in the sediments of a typical inland hypersaline chloride-sulfate lake was performed to broaden our view of the diversity of halophilic autotrophic populations.

\section{METHODS}

Bacterial strains and environmental samples. Two type strains of the genus Halothiobacillus, Halothiobacillus hydrothermalis and Halothiobacillus halophilus, were obtained from the German Culture Collection DSMZ. Other strains of halophilic SOB, represented by seven genera of the Gammaproteobacteria, have been described previously (Sorokin et al., 2006a, b, 2007a, b, 2008a, b) and are maintained in our active culture collection. Sediment samples were taken from the hypersaline lake Burlinskoe (Kulunda Steppe, Altai, Russia) and kept at $4{ }^{\circ} \mathrm{C}$ before use. The lake brine had a pH of 7.45 and a total salt content of $360 \mathrm{~g} \mathrm{l}^{-1}$ with absolute domination of $\mathrm{NaCl}$; the lake is a local resource for cooking salt.
DNA isolation. Genomic DNA was extracted from the pure cultures of halophilic SOB with an UltraClean Microbial DNA Isolation kit (MoBio Laboratories) according to the manufacturer's protocol. To extract DNA from salt lake sediments, the PowerSoil DNA Isolation kit (MoBio Laboratories) was used. Approximately 10 g sediment was washed twice with $1 \mathrm{M} \mathrm{NaCl}$. Then, $1 \mathrm{ml}$ of the fine clay fraction was separated from the coarse sandy fraction by three cycles of homogenization/low-speed centrifugation. Subsequently, the fine fraction was used for DNA isolation.

Amplification and cloning of the cbbL and cbbM genes from pure cultures and environmental samples. To amplify the $c b b L$ genes, several primer pairs were used (see Table 1). Some of the primers were newly constructed on the basis of the alignment of $c b b L /$ $c b b M$ sequences derived from GenBank. Each $c b b L$ and $c b b M$ alignment consisted of about 100 RuBisCO sequences from chemoand photoautotrophic bacteria. Degenerate primers were designed from conserved regions. Amplification was performed in $50 \mu \mathrm{l}$ reaction mixtures containing $25 \mu \mathrm{l}$ Taq PCR Master Mix (Qiagen), $\mathrm{MgCl}_{2}$ (3 mM final concentration) and $25 \mathrm{pmol}$ each of forward and reverse primers. The PCR conditions for amplification of the $c b b L$ gene were as follows: an initial DNA denaturation at $94{ }^{\circ} \mathrm{C}$ for $3 \mathrm{~min}$, followed by 25 cycles of denaturation at $94{ }^{\circ} \mathrm{C}$ for $30 \mathrm{~s}$, a decrease of the annealing temperature from 58 to $48{ }^{\circ} \mathrm{C}$ for $30 \mathrm{~s}$, and an extension at $72{ }^{\circ} \mathrm{C}$ for $45 \mathrm{~s}$. In addition, another 10 cycles of $94{ }^{\circ} \mathrm{C}$ for $20 \mathrm{~s}, 48{ }^{\circ} \mathrm{C}$ for $20 \mathrm{~s}$ and $72{ }^{\circ} \mathrm{C}$ for $45 \mathrm{~s}$ were performed, followed by a final extension at $72{ }^{\circ} \mathrm{C}$ for $7 \mathrm{~min}$. The amplification of the $c b b M$ gene was performed under the same conditions, but the annealing temperature was lowered from 62 to $52{ }^{\circ} \mathrm{C}$. The PCR products were subjected to $1.2 \%(\mathrm{w} / \mathrm{v})$ agarose gel electrophoresis, stained with ethidium bromide and visualized by UV excitation. The PCR products of the expected size were purified and sequenced directly (for pure cultures) or used for cloning (for the products obtained from the sediment samples).

Clone libraries were constructed using the TOPO TA cloning kit and Escherichia coli TOP10 competent cells (Invitrogen Life Technologies) according to the manufacturer's protocol. From each clone library, 50 clones were selected randomly and screened for the presence of inserts of the expected size by PCR using the vector-specific primer pair M13Fwd/M13Rev. Purified PCR products were sequenced directly by a commercial company (Marcogen, Korea).

Comparative sequence analysis. Preliminary analysis of the new sequences was done in BLAST (http://www.ncbi.nlm.nih.gov/blast/), metagenomic databases at the Joint Genome Institute (Markowitz et al., 2006) and CAMERA (Seshadri et al., 2007). The nucleotide and inferred amino acid sequences were aligned with sequences from GenBank using CLUSTAL w (Thompson et al., 1994). Phylogenetic trees were reconstructed using two different algorithms: neighbour-joining in the TREECONW program package (Van de Peer \& De Wachter, 1994), and maximum-likelihood using PhyML software (Guindon \& Gascuel, 2003). Calculations of rarefaction curves were performed with the Analytic Rarefaction freeware program (http://www.uga.edu/ strata/software/Software.html). A homologous coverage was estimated according to Singleton et al. (2001).

\section{RESULTS}

\section{Detection of the cbb genes in pure cultures of halophilic SOB}

At first, the detection of $c b b$ genes in pure cultures of halophilic SOB was attempted using the primer set RubIgF/RubIgR specific for the 'green-like' $c b b L$ form I 
Table 1. Overview of oligonucleotide primers for amplification of the different RuBisCO genes

\begin{tabular}{|c|c|c|c|c|}
\hline Primer & RuBisCO form & Sequence $\left(5^{\prime}-3^{\prime}\right)$ & Position $^{*}$ & Reference or source \\
\hline cbbLG1f & Form I 'green-like' $c c b L$ & GGC AAC GTG TTC GGS TTC AA & $343-362$ & Selesi et al. (2005) \\
\hline cbbL1106r & & CRT GRA TVC CRC CIG AIG CIA CVG & $1106-1129$ & This study \\
\hline RubIgF & & GAY TTC ACC AAR GAY GAY GA & $571-590$ & Spiridonova et al. (2004) \\
\hline RubIgR & & TCR AAC TTG ATY TCY TTC CA & $1363-1382$ & Spiridonova et al. (2004) \\
\hline gr184f & & GGN ACN TGG ACC ACN GTN TGG AC & $169-191$ & Modified after Alfreider et al. (2003) \\
\hline gr781r & & GTA RTC GWG CAT GAY GAT SGG & $766-786$ & Modified after Alfreider et al. (2003) \\
\hline RubII331f & Form II $c b b M$ & AAC AAC CAR GGY ATG GGY GA & $331-350$ & This study \\
\hline RuIIR2 & & TGR CCI GCI CGR TGR TAR TGCA & $851-872$ & Spiridonova et al. (2004) \\
\hline RubII1113r & & SGC GTT CAT GCC SSA GAT GAT CGG SGT & $1090-1119$ & Modified after Elsaied et al. (2007) \\
\hline
\end{tabular}

${ }^{\star}$ The form I primer positions correspond to the nucleotide sequence of the Acidithiobacillus ferrooxidans cbbL gene (AF307091). cbbM primer positions correspond to the nucleotide sequences of the $c b b M$ gene of Rhodospirillum rubrum (X002860).

(Spiridonova et al., 2004). Despite the good results previously obtained with these primers for the haloalkaliphilic SOB (Tourova et al., 2006, 2007), they gave positive amplification among the halophilic SOB only for representatives of the genera Halothiobacillus, Thiohalomonas, Thiohalophilus and Thiohalobacter. Of the other primer pairs tested (Table 1), the one specific for the 'green-like' form IA (Alfreider et al., 2003) gave the best results, but the amplified $c b b L$ fragment only had a small overlap with the fragments obtained with the RubIgF/RubIgR primers and with most of the $c b b L$ sequences deposited in GenBank. Therefore, we designed an additional set of primers to amplify the $c b b L$ gene in representatives of the genera Thiohalospira, Thiohalorhabdus and Thioalkalibacter. This set consisted of primer $c b b L G 1 f$ (Selesi et al., 2005) and a newly designed reverse primer, $c b b L 1106$. The 'green-like' type $1 \mathrm{~A}$ RubisCO was successfully detected in all tested strains of halophilic SOB except for Thiohalomonas nitratireducens. The common region of the $c b b L$ fragments was aligned, resulting in a total of $513 \mathrm{nt}$ or 171 aa that was used for phylogenetic analysis (Supplementary Figs S1 and S3).

The primer set RuIIF2/RuIIR2 (Spiridonova et al., 2004) used in our previous work for the detection of the $c b b M$ gene was inefficient for the investigated strains of halophilic SOB. Better results were obtained using a combination of the newly designed forward primer RubII331f and a modified version of the reverse primer (RubII1113r) described by Elsaied et al. (2007) (Table 1). This primer pair was successfully tested for the amplification of the $c b b M$ gene from most of the pure cultures of halophilic $\mathrm{SOB}$ and from several photoautotrophic bacteria harbouring the form II RuBisCO. However, amplification of the $c b b M$ in Thiohalorhabdus denitrificans HL19 and Thiohalospira halophila HL21 was successful only with the primer combination RuII331f/RuIIR2. In contrast to the primers for the $c b b L$ gene, which were used to detect all investigated strains except for Thiohalomonas nitratireducens, the primer pairs for the $c b b M$ gene only gave positive results for the genus Thiohalomonas and for some strains of the genera Halothiobacillus, Thiohalospira and Thiohalorhabdus. The common region of the $c b b M$ fragments was aligned, resulting in a total of $477 \mathrm{nt}$ or 159 aa that was used for phylogenetic analysis (Supplementary Figs S2 and S4).

\section{Phylogenetic analysis}

According to the 16S rRNA gene-based phylogeny, the investigated halophilic SOB groups represent deep lineages within the Gammaproteobacteria not related to each other or to other groups (Fig. 1). Among them, only the genera Halothiobacillus and Thioalkalibacter (Halothiobacillaceae) and Thiohalospira (Ectothiorhodospiraceae) are currently classified as members of the Chromatiales, while the other groups remain unassigned. The general topology of the CbbL and CbbM trees (Fig. 2) differed from that of the $16 \mathrm{~S}$ rRNA gene tree (Fig. 1), but the clustering pattern within most of the groups was similar. In particular, most groups of halophilic SOB branched as novel deep lineages within the Gammaproteobacteria (Supplementary Fig. S5). However, the majority of strains formed monophyletic $c b b L$ clusters at the species level, with amino acid sequence identities ranging from 97 to $100 \%$. However, there were also examples of incongruence between the 16S rRNA- and $c b b L$-based phylogenies at the species level. Two strains of Thiohalospira halophila (HL4 and HL21) and Thiohalospira alkaliphila grouped with photo- and chemotrophic Gammaproteobacteria centred around the CbbL-2 of Allochromatium vinosum ('A. vinosum group'). This is a good illustration of how ambiguous the phylogenetic assignment of an organism might be if based on either a single functional gene or a single strain. Another example was found within the genus Halothiobacillus. The $c b b L$ sequences from this group formed a single cluster when amino acid sequences were used for phylogenetic analysis (Fig. 2), while the cluster was disintegrated when nucleotide sequences were used (data not shown). Finally, the facultatively alkaliphilic halophile Thioalkalibacter halophilus is a member of the Halothiobacillus group, according to the $16 \mathrm{~S}$ rRNA-based phylogeny. However, the $c b b L$ gene of Thioalkalibacter halophilus was closely related to one of the two $c b b L$ genes of Thiomicrospira halophila. 


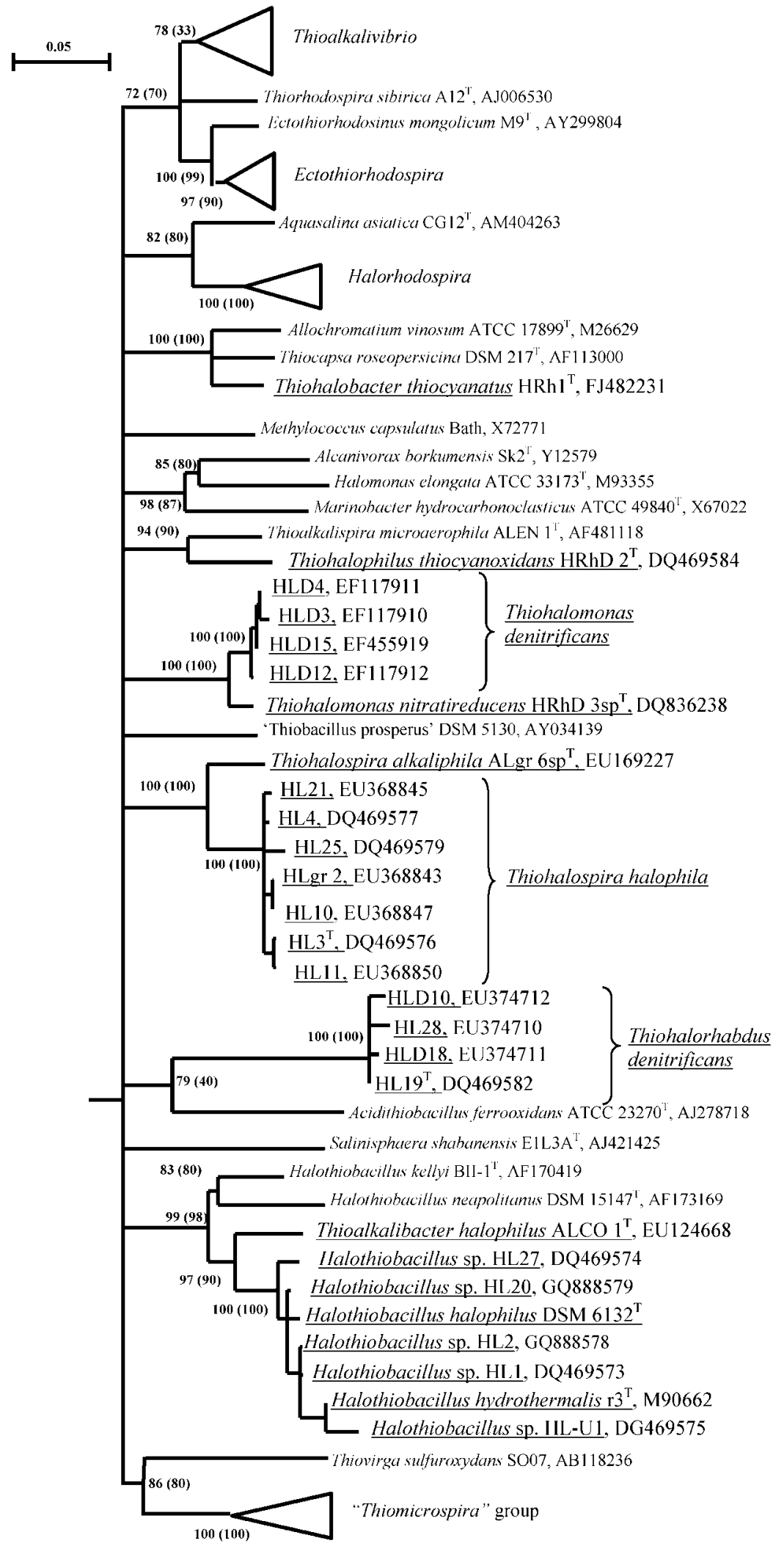

Fig. 1. Phylogenetic tree based on $16 \mathrm{~S}$ rRNA gene sequences, showing the phylogenetic affiliation of representative strains of halophilic SOB from hypersaline habitats within the Gammaproteobacteria. The strains for which RuBisCO gene sequences were determined are underlined. Tree topography and evolutionary distances are given by the neighbourjoining method with Jukes-Cantor distances. Numbers at the nodes indicate the percentage of bootstrap values for the clade in 1000 replications (the values for the maximumlikelihood method are given in parentheses). Only values above $70 \%$ are shown.
The results of the $c b b M$ gene analysis only partially correlated with the $c b b L$ phylogeny. In particular, the newly isolated Halothiobacillus strains HL1, HL2 and HL27 and members of the genus Thiohalomonas formed separate clusters with high internal amino acid sequence identities between 92 and 99\% (Fig. 3 and Supplementary Fig. S6). 


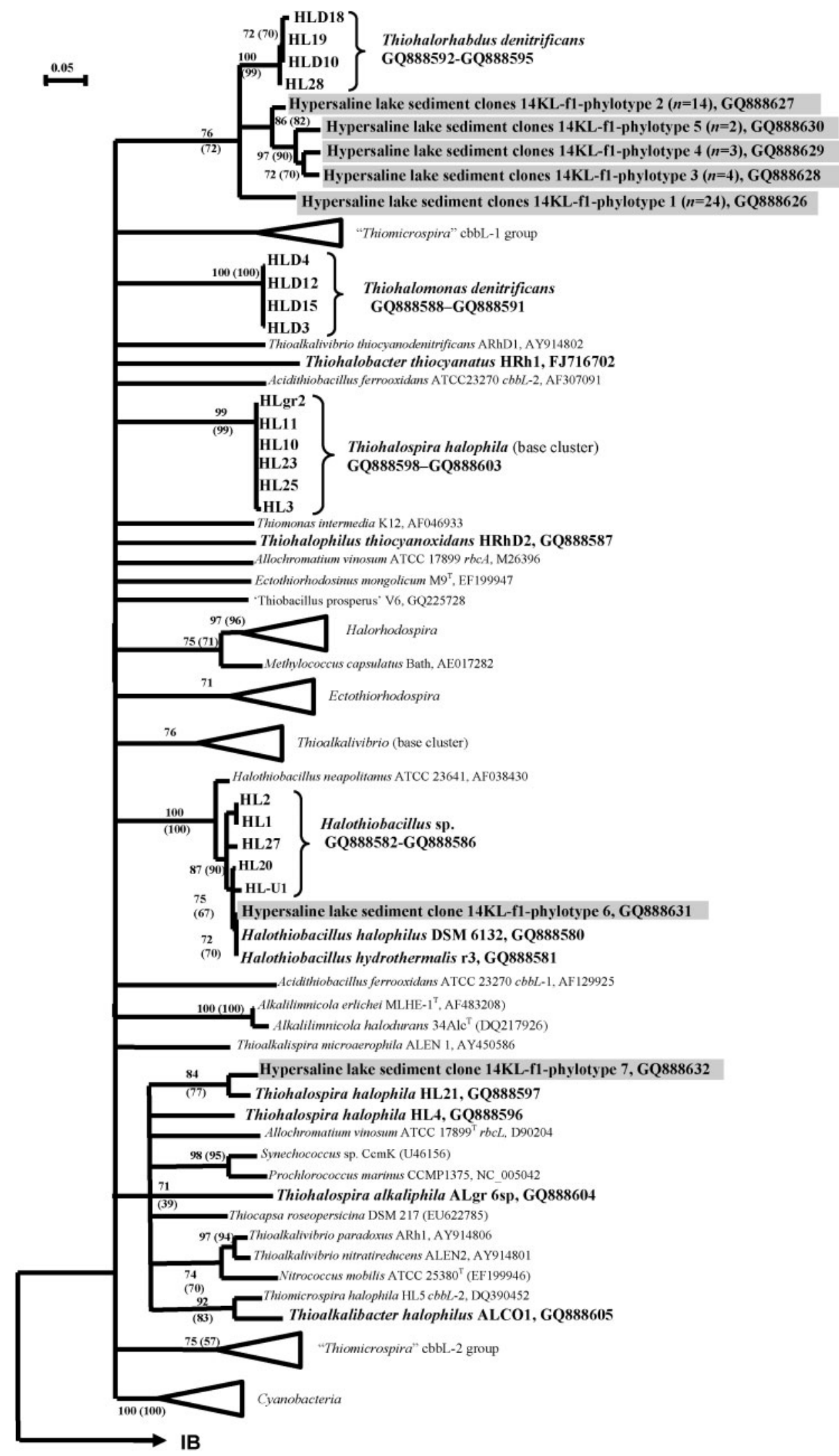


Fig. 2. Phylogenetic tree based on CbbL sequences, showing the position of representative strains of halophilic SOB in relation to environmental sequences from hypersaline lake Burlinskoe (Kulunda Steppe). The CbbL sequences obtained in this study are in bold type (pure cultures) or highlighted in grey (environmental clones). Tree topology and evolutionary distances are given by the neighbour-joining method with Poisson distances. Numbers at the nodes indicate the percentage of bootstrap values for the clade in 1000 replications (the values for the maximum-likelihood method are given in parentheses). Only values above $70 \%$ are shown.

The cluster composed of strains HL1, HL2 and HL27 is separated from the type species Halothiobacillus neopolitanus ATCC 23641 and CbbM sequences of the thioautotrophic bacteria formerly included in the genus Thiobacillus (now reclassified as the genera Acidithiobacillus, Thiomonas and Thiobacillus). However, the most obvious deviation between the $c b b M$-based phylogeny and those of the 16S rRNA and $c b b L$ genes was the branching position of the genera Thiohalospira and Thiohalorhabdus. Being distantly related according to the phylogenies of the $16 \mathrm{~S}$ rRNA and $c b b L$ genes, they formed a single deeply branching lineage in the CbbM phylogeny, with internal CbbM sequence identities of 96 to $100 \%$ (Fig. 3 and Supplementary Fig. S6).

\section{Detection of $c b b$ genes in sediments of a hypersaline lake}

By analysing the $c b b$ genes of various halophilic $\mathrm{SOB}$ isolated from hypersaline habitats the existing database has been substantially increased. One of the obvious directions to continue this work was to go back to the environment from which the pure cultures of halophilic SOB were obtained and to compare the $c b b$ gene diversity in situ with the diversity obtained with the cultivation approach. For this we chose the most typical inland hypersaline lake from the investigated set (Kulunda Steppe, Altai, Russia), which yielded all culturable forms of halophilic SOB described previously by this group, including Thiohalophilus, Thiohalorhabdus, Thiohalomonas, Thiohalospira and Halothiobacillus. By using the cbbLG1f/ $c b b L 1106 \mathrm{r}$ and RubII331f/RuIIR2 primer sets, $49 c b b L$ and $48 c b b M$ clones were recovered from the sample. Their phylogenetic analyses revealed seven phylotypes based on a nucleotide sequence identity cut-off of $99 \%$. The rarefaction curves (Fig. 4) did not reach clear saturation, indicating that further analysis of a larger number of clones would have revealed some additional diversity. An underestimate of the diversity was expected, as the coverages of the libraries were estimated to be 85.7 and $84.4 \%$, respectively.

The amplicons of the $c b b L$ gene all belonged to the 'greenlike' form (IA) of RuBisCO. This form is mainly found in Alpha-, Beta- and Gammaproteobacteria, although a few cyanobacterial sequences also belong to form IA (Watson \& Tabita, 1997). None of the obtained $c b b L$ sequences showed high similarity to sequences in GenBank $(<85 \%$ nucleotide identity), indicating the presence of previously unknown autotrophic species. However, they were clearly related to the newly obtained sequences from pure cultures of halophilic SOB (Fig. 2). The five most abundant $c b b L$ phylotypes $(96 \%$ of the total) were affiliated with the extremely halophilic deep-lineage SOB Thiohalorhabdus. These sequences formed a single cluster closely related to the $c b b L$ sequences of Thiohalorhabdus denitrificans, but represented new branches in this cluster (86.6-96.7\% sequence identity to the $c b b L$ gene of Thiohalorhabdus denitrificans). The sequence of one of the minor $c b b L$ phylotypes in the clone library was almost identical to the cbbL gene of Halothiobacillus halophilus, and another minor $c b b L$ phylotype was related to the atypical $c b b L$ gene from Thiohalospira halophila (strains HL4 and HL21).

Amplicons of the $c b b M$ gene were more diverse (Fig. 3). The two most abundant $c b b M$ phylotypes in the clone library ( $77 \%$ of the total) were affiliated to the $c b b M$ gene of Thiohalorhabdus denitrificans, which correlated well with the results of the $c b b L$-based survey. The $c b b M$ phylotype belonging to the genus Halothiobacillus was also present in the clone library as a minor phylotype. Some $c b b M$ phylotypes, however, did not show significant similarity to any sequences in GenBank or to the sequences of halophilic SOB and formed three independent novel branches within the $c b b M$ tree.

\section{DISCUSSION}

Among the chemolithoautotrophic bacteria, the SOB have one of the most efficient catabolisms, which allows them to deal with extreme conditions. This might explain the surprisingly high culturable diversity of moderate to extreme halophilic SOB recently found in hypersaline lakes and salterns (Sorokin et al., 2006a; Sorokin, 2008). However, despite the relatively high viable cell counts (up to $10^{6}$ $\mathrm{ml}^{-1}$ ), direct detection of this important functional group in hypersaline sediments using the $16 \mathrm{~S}$ rRNA gene as a molecular marker has proved to be inefficient (our unpublished data). Therefore, the use of genes encoding functional proteins is a better alternative. In the chemolithoautotrophic Proteobacteria, autotrophic carbon fixation via the Calvin-Benson cycle is an obvious target. Although the RuBisCO phylogeny, in general, differs from the traditional 16S rRNA gene-based phylogeny of autotrophic bacteria (Watson \& Tabita, 1997), our analysis of the $c b b$ genes in halophilic SOB confirms their independent deep-lineage position within the Gammaproteobacteria.

Another conclusion from the pure culture study is that the presence of multiple $c b b$ genes in a single $\mathrm{SOB}$ species is a common phenomenon. This has been shown previously for other SOB species, such as Acidithiobacillus ferrooxidans, Thiobacillus sp. (English et al., 1992), Halothiobacillus 


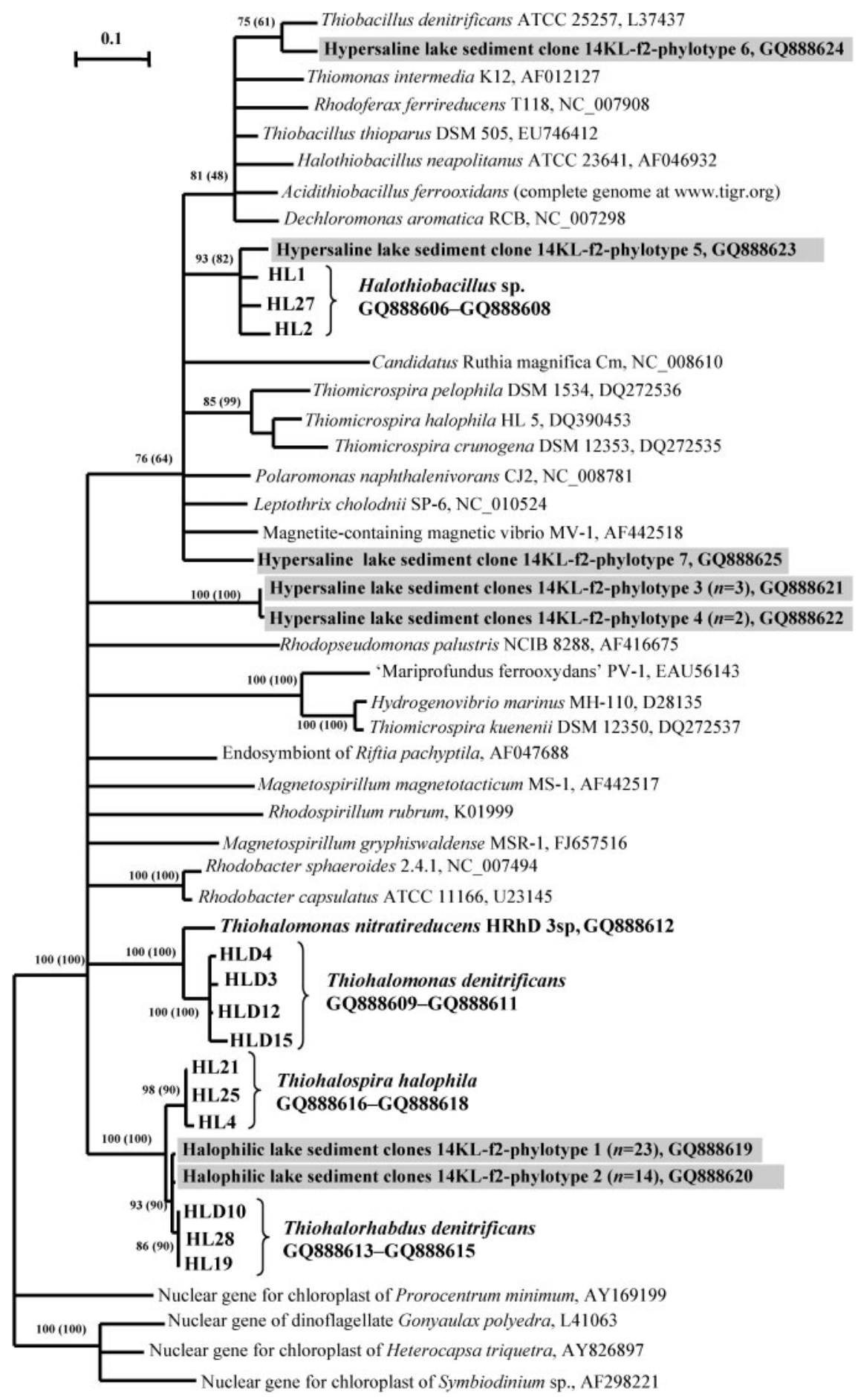

Fig. 3. Phylogenetic tree based on CbbM sequences, showing the position of representative strains of halophilic SOB in relation to environmental sequences from hypersaline lake Burlinskoe (Kulunda Steppe). The sequences obtained in this study are in bold type (pure cultures) or highlighted in grey (environmental clones). Tree topology and evolutionary distances are given by the neighbour-joining method with Poisson distances. Numbers at the nodes indicate the percentage of bootstrap values for the clade of this group in 1000 replications (the values for the maximum-likelihood method are given in parentheses). Only values above $70 \%$ are shown. 


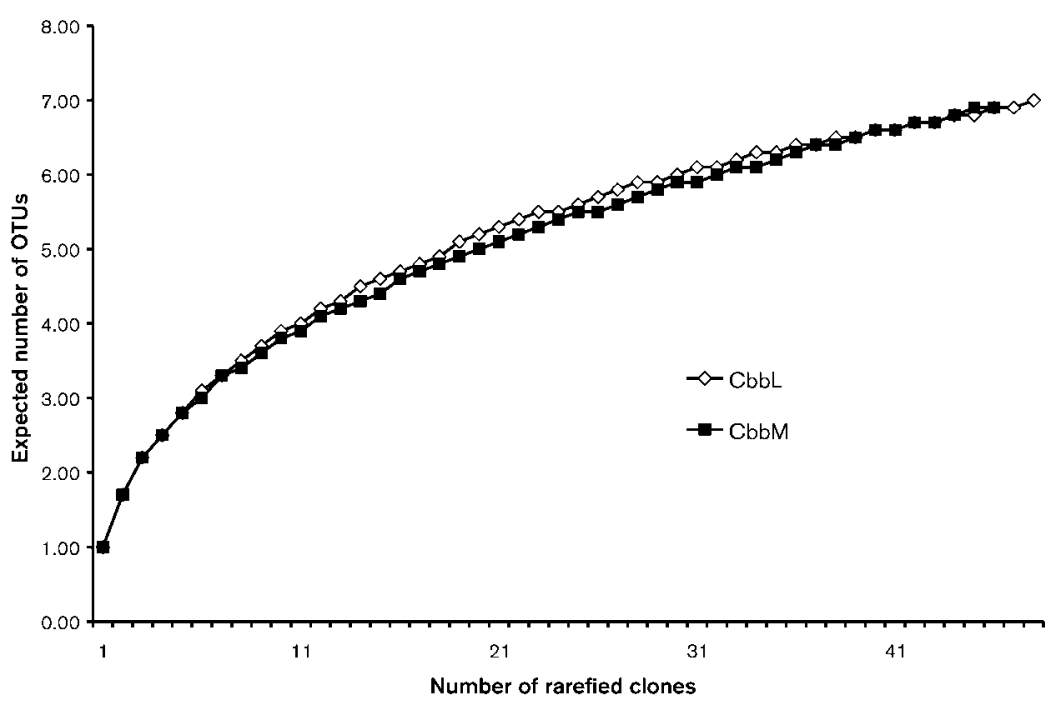

Fig. 4. Rarefaction curves for the $c b b L$ and cbbM gene sequences obtained from hypersaline lake sediments.

neapolitanus (Baker et al., 1998), Thiomonas intermedia (Stoner \& Shively, 1993) and Thiomicrospira sp. (Tourova et al., 2006). However, most of the evidence was obtained for a single strain of a single species. Only for Acidithiobacillus ferrooxidans have two closely related strains been tested (Cannon et al., 2003). Both strains contained two $c b b L$ genes and a single $c b b M$ gene. Both $c b b L$ and $c b b M$ showed high sequence identities between the two strains. We expected to find analogous results. However, the analysis of a large set of halophilic SOB strains closely related according to $16 \mathrm{~S}$ rRNA gene sequence similarity demonstrated that only in the genus Thiohalomonas were the $c b b$ and 16S rRNA gene phylogenies consistent, and all four strains of Thiohalomonas denitrificans contained nearly identical $c b b L$ and $c b b M$ genes. At the same time another species of the same genus differed significantly in its $c b b$ gene set: in Thiohalomonas nitratireducens the $c b b L$ gene was not detectable by any primer sets and so either is absent or differs significantly from those present in the type species Thiohalomonas denitrificans. Among the other halophilic SOB genera, the situation with $c b b$ was more complicated, varying even on the level of strains of the same species. Similar 'mosaic' situations were found in the genera Thiohalospira and Thiohalorhabdus. In Thiohalospira the detected CbbL sequences of all tested strains divided into two distinct clusters, in contrast to CbbM, which formed a single cluster with the $c b b M$ sequences of Thiohalorhabdus denitrificans, despite the obvious lack of a 16S rRNA-based phylogenetic relationship. Although this might be the result of the limitations of PCR detection, the differences in gene structure for a key functional gene among closely related strains are worth investigating further, since investigations are usually limited to the type strain.

The presence of two different $c b b L$ phylotypes in strains of Thiohalospira halophila could be the result of an ancient gene duplication with subsequent selection of one of the duplicates, similar to other SOB, such as Thiomicrospira and Acidithiobacillus. This might be proven by finding a Thiohalospira strain that bears both $c b b L$ genes. On the other hand, the $c b b L$ sequences of strains HL4/HL21 cluster with the group of Allochromatium vinosum, encompassing various unrelated chemo- and photoautotrophic bacteria, and the substantial level of sequence divergence within the group might indicate lateral $c b b L$ gene transfer (Watson \& Tabita, 1997; Tourova et al., 2007, 2009). Lateral $c b b$ gene transfer might be the reason for the isolated position of Halothiobacillus neapolitanus and Thioalkalibacter halophilus among halophilic SOB on the $c b b L$ tree. The $\mathrm{G}+\mathrm{C}$ content of these strains is lower than that of other halophilic SOB species; they are close to Thiomicrospira halophila HL5.

Lateral gene transfer is more obviously the reason for the high sequence similarity between the $c b b M$ genes of two otherwise unrelated genera of extremely halophilic SOB, Thiohalospira and Thiohalorhabdus. Furthermore, variation of the $c b b$ composition within a single species of these genera indicates that parallel to the $c b b M$ transfer some of the donor strains have lost the gene completely. The latter might be a consequence of adaptation to a more aerobic lifestyle with a lower $\mathrm{CO}_{2}$ concentration, which favours form I RuBisCO.

The results obtained with the different strains of halophilic SOB allowed the successful identification of the environmental $c b b$ sequences retrieved from a typical inland hypersaline lake. Without the sequence information from cultured SOB, the environmental sequences would have been 'hanging in the air'. None of the halophilic SOB phylotypes detected by cultivation or molecular techniques in the chloride-sulfate hypersaline lakes with neutral $\mathrm{pH}$ was related to those SOB found previously to be present in the saline alkaline Mono Lake (Giri et al., 2004). All the $c b b L$ sequences obtained from samples from Mono Lake were related to the alkaliphilic SOB Thioalkalivibrio and Thioalkalimicrobium, which are typical inhabitants of soda lakes. 
The results of our environmental $c b b L$ survey suggest the predominance of phylotypes related to the extremely halophilic Thiohalorhabdus-Thiohalospira cluster. The former genus, which is difficult to cultivate, is probably the most abundant SOB species in the hypersaline lake sediments, since it was detetcted by two independent PCR assays, one for $c b b L$ and the other for $c b b M$. Interestingly, the $c b b$ screening revealed different Thiohalorhabdus branches from those obtained from the isolated strains. However, the number of different $c b b M$ phylotypes was less than that of $c b b L$. Other genera, such as Thiohalospira and Halothiobacillus, detected as minor $c b b$ components of the clone libraries, dominated the aerobic cultures. The latter discrepancy may suggest that aerobic conditions are rare in the investigated lake sediments. This is confirmed by the presence of high sulfide concentrations (up to $1 \mathrm{mM}$ ) in the top $5 \mathrm{~cm}$ layer of the sediments. On the other hand, the complete absence of $c b b$ sequences corresponding to the genus Thiohalomonas, consistently dominant in cultures at moderate salinity and under denitrifying conditions, might indicate that under in situ conditions nitrate is not freely available for this SOB type, limiting its proliferation. Indeed, it is a well-documented fact that nitrification is arrested at a salinity above $1 \mathrm{M} \mathrm{NaCl}$ (Oren, 1999).

Concluding, almost all halophilic lithoautotrophic SOB strains isolated from hypersaline lakes were shown to possess $c b b L$, while the detection of $c b b M$ failed for some of the strains. Furthermore, in general, $c b b$ genes are useful markers for the detection and identification of autotrophic $\mathrm{SOB}$ species in their habitats.

\section{ACKNOWLEDGEMENTS}

This work was supported by a Federation of European Microbiological Societies (FEMS) Fellowship grant to O.L.K. and by Russian Foundation for Basic Research (RFBR) grants 07-04-00153 and 08-04-00005.

\section{REFERENCES}

Alfreider, A., Vogt, C., Hoffmann, D. \& Babel, W. (2003). Diversity of ribulose-1,5-bisphosphate carboxylase/oxygenase large-subunit genes from groundwater and aquifer microorganisms. Microb Ecol 45, 317328.

Baker, S. H., Jin, S., Aldrich, H. C., Howard, G. T. \& Shively, J. M. (1998). Insertion mutation of the form I $c b b L$ gene encoding ribulose bisphosphate carboxylase/oxygenase (RuBisCO) in Thiobacillus neapolitanus results in expression of form II RuBisCO, loss of carboxysomes, and an increased $\mathrm{CO}_{2}$ requirement for growth. J Bacteriol 180, 4133-4139.

Banciu, H. L., Sorokin, D. Y., Tourova, T. P., Galinski, E. A., Muntyan, M. S., Kuenen, J. G. \& Muyzer, G. (2008). Influence of salts and pH on growth and activity of a novel facultatively alkaliphilic, extremely salttolerant, obligately chemolithoautotrophic sufur-oxidizing Gammaproteobacterium Thioalkalibacter halophilus gen. nov., sp. nov. from South-Western Siberian soda lakes. Extremophiles 12, 391-404.

Cannon, G. C., Baker, S. H., Soyer, F., Johnson, D. R., Bradburne, C. E., MehIman, J. L., Davies, P. S., Jiang, Q. L., Heinhorst, S. \& Shively, J. M.
(2003). Organization of carboxysome genes in the thiobacilli. Curr Microbiol 46, 115-119.

Elsaied, H. E., Kimura, H. \& Naganuma, T. (2007). Composition of archaeal, bacterial, and eukaryal RuBisCO genotypes in three Western Pacific arc hydrothermal vent systems. Extremophiles 11, 191-202.

English, R. S., Williams, C. A., Lorbach, S. C. \& Shively, J. M. (1992). Two forms of ribulose-1,5-bisphosphate carboxylase/oxygenase from Thiobacillus denitrificans. FEMS Microbiol Lett 73, 111-119.

Friedrich, C. G., Rother, D., Bardischewsky, F., Quentmeier, A. \& Fischer, J. (2001). Oxidation of reduced inorganic sulfur compounds by bacteria: emergence of a common mechanism? Appl Environ Microbiol 67, 2873-2882.

Friedrich, C. G., Bardischewsky, F., Rother, D., Quentmeier, A. \& Fischer, J. (2005). Prokaryotic sulfur oxidation. Curr Opin Microbiol 8, 253-259.

Giri, B. J., Bano, N. \& Hollibaugh, J. T. (2004). Distribution of RuBisCO genotypes along a redox gradient in Mono Lake, California. Appl Environ Microbiol 70, 3443-3448.

Guindon, S. \& Gascuel, O. (2003). A simple, fast, and accurate algorithm to estimate large phylogenies by maximum likelihood. Syst Biol 52, 696-704.

Loy, A., Duller, S., Baranyi, C., Mußmann, M., Ott, J., Sharon, I., Béjà, O. \& Le Paslier, D. (2009). Reverse dissimilatory sulfite reductase as phylogenetic marker for a subgroup of sulfur-oxidizing prokaryotes. Environ Microbiol 11, 289-299.

Markowitz, V. M., Ivanova, N., Palaniappan, K., Szeto, E., Korzeniewski, F., Lykidis, A., Anderson, I., Mavromatis, K., Kunin, V. \& other authors (2006). An experimental metagenome data management and analysis system. Bioinformatics 22, e359-e367.

Oren, A. (1999). Bioenergetic aspects of halophilism. Microbiol Mol Biol Rev 63, 334-348.

Selesi, D., Schmid, M. \& Hartmann, A. (2005). Diversity of green-like and red-like ribulose-1,5-bisphosphate carboxylase/oxygenase largesubunit genes $(c b b L)$ in differently managed agricultural soils. Appl Environ Microbiol 71, 175-184.

Seshadri, R., Kravitz, S. A., Smarr, L., Gilna, P. \& Frazier, M. (2007). CAMERA: a community resource for metagenomics. PLoS Biol 5, e75.

Singleton, D. R., Furlong, M. A., Rathbun, S. L. \& Whitman, W. B. (2001). Quantitative comparisons of 16S rRNA gene sequence libraries from environmental samples. Appl Environ Microbiol 67, 4374-4376.

Sorokin, D. Y. (2008). Diversity of halophilic sulfur-oxidizing bacteria in hypersaline habitats. In Microbial Sulfur Metabolism, pp. 225-237, edited by C. Dahl \& C. G. Friedrich. Proceedings of the International Symposium on Microbial Sulfur Metabolism, 29 June to 2 July 2006, Münster, Germany. Berlin: Springer.

Sorokin, D. Y., Tourova, T. P., Lysenko, A. M. \& Muyzer, G. (2006a). Diversity of culturable halophilic sulfur-oxidizing bacteria in hypersaline habitats. Microbiology 152, 3013-3023.

Sorokin, D. Y., Tourova, T. P., Kolganova, T. V., Spiridonova, E. M., Berg, I. A. \& Muyzer, G. (2006b). Thiomicrospira halophila sp. nov., a moderately halophilic, obligately chemolithoautotrophic, sulfuroxidizing bacterium from hypersaline lakes. Int J Syst Evol Microbiol 56, 2375-2380.

Sorokin, D. Y., Tourova, T. P., Bezsoudnova, E. Y., Pol, A. \& Muyzer, G. (2007a). Denitrifcation in a binary culture and thiocyanate metabolism in Thiohalophilus thiocyanoxidans gen. nov. sp. nov. - a moderately halophilic chemolithoautotrophic sulfur-oxidizing Gammaproteobacterium from hypersaline lakes. Arch Microbiol 187, 441-450. 
Sorokin, D. Y., Tourova, T. P., Braker, G. \& Muyzer, G. (2007b). Thiohalomonas denitrificans gen. nov., sp. nov. and Thiohalomonas nitratireducens sp. nov., novel obligately chemolithoautotrophic, moderately halophilic, thiodenitrifying Gammaproteobacteria from hypersaline habitats. Int J Syst Evol Microbiol 57, 1582-1589.

Sorokin, D. Y., Tourova, T. P., Muyzer, G. \& Kuenen, G. J. (2008a). Thiohalospira halophila gen. nov., sp. nov. and Thiohalospira alkaliphila sp. nov., novel obligately chemolithoautotrophic, halophilic, sulfur-oxidizing gammaproteobacteria from hypersaline habitats. Int J Syst Evol Microbiol 58, 1685-1692.

Sorokin, D. Y., Tourova, T. P., Galinski, E. A., Muyzer, G. \& Kuenen, J. G. (2008b). Thiohalorhabdus denitrificans gen. nov., sp. nov., an extremely halophilic, sulfur-oxidizing, deep lineage gammaproteobacterium from hypersaline habitats. Int J Syst Evol Microbiol 58, 2890-2897.

Sorokin, D. Y., Kovaleva, O. L., Tourova, T. P. \& Muyzer, G. (2010). Thiohalobacter thiocyanaticus gen. nov., sp. nov., a moderately halophilic, sulfur-oxidizing gammaproteobacterium from hypersaline lakes, that utilizes thiocyanate. Int J Syst Evol Microbiol 60, 444-450.

Spiridonova, E. M., Berg, I. A., Kolganova, T. V., Ivanovsky, R. N., Kuznetsov, B. B. \& Tourova, T. P. (2004). An oligonucleotide primer system for amplification of the ribulose-1,5-bisphosphate carboxylase/oxygenase genes of bacteria of various taxonomic groups. Mikrobiologiia 73, 377-387.

Stoner, M. T. \& Shively, J. M. (1993). Cloning and expression of the Dribulose-1,5-bisphosphate carboxylase/oxygenase form II gene from Thiobacillus intermedius in Escherichia coli. FEMS Microbiol Lett 107, 287-292.
Thompson, J. D., Higgins, D. G. \& Gibson, T. J. (1994). Clustal W: improving the sensitivity of progressive multiple sequence alignment through sequence weighting, position-specific gap penalties and weight matrix choice. Nucleic Acids Res 9, 3251-3270.

Tourova, T. P., Spiridonova, E. M., Berg, I. A., Kuznetsov, B. B. \& Sorokin, D. Yu. (2006). Occurrence, phylogeny and evolution of ribulose-1,5-bisphosphate carboxylase/oxygenase genes in obligately chemolithoautotrophic sulfur-oxidizing bacteria of the genera Thiomicrospira and Thioalkalimicrobium. Microbiology 152, 21592169.

Tourova, T. P., Spiridonova, E. M., Berg, I. A., Slobodova, N. V., Boulygina, E. S. \& Sorokin, D. Y. (2007). Phylogeny and evolution of the family Ectothiorhodospiraceae based on comparison of $16 \mathrm{~S}$ rRNA, $c b b L$ and nifH gene sequences. Int J Syst Evol Microbiol 57, 2387-2398.

Tourova, T. PKeppen, O. IKovaleva, O. LSlobodova, N. VBerg, I. Alvanovsky, R. N (2009). Phylogeny of the purple sulfur bacterium Thiocapsa sp. strain BBS on the basis of analysis of $16 \mathrm{~S}$ rRNA, $c b b L$ and nifH and description of new species Thiocapsa bogorovii sp.nov. Mikrobiologiia 78, 381-392.

Van de Peer, Y. \& De Wachter, R. (1994). TREeCON for Windows: a software package for the construction and drawing of evolutionary trees for the Microsoft Windows environment. Comput Appl Biosci 10, 569-570.

Watson, G. M. F. \& Tabita, F. R. (1997). Microbial ribulose 1, 5-bisphosphate carboxylase/oxygenase: a molecule for phylogenetic and enzymological investigation. FEMS Microbiol Lett 146, 13-22.

Edited by: W. Liesack 